\title{
EPOPEIA E ROMANCE EM CONFLITO? O FELIZ INDEPENDENTE (1779), DE TEODORO DE ALMEIDA
}

\author{
EPOS AND NOVEL IN CONFLICT? \\ TEODORO DE ALMEIDA'S THE HAPPY INDEPENDENT (1779)
}

Markus Ebenhoch ${ }^{1}$

\begin{abstract}
Resumo: A análise da narrativa híbrida $O$ feliz independente (1779), de Teodoro de Almeida, revela como a poesia épica em Portugal já estava num processo de renovação perto do final do século XVIII, colocando pistas para o romance histórico do Romantismo. As reflexões metaliterárias do mesmo autor e o discurso poetológico que acompanhou a publicação mostram o status volátil de alguns paradigmas do gênero épico, por exemplo, o uso do verso, os feitos heroicos com relevância para uma coletividade ou a conceção do herói. Para os contemporâneos, a obra de Almeida é um "poema épico em prosa", hoje em dia classificamo-la como "romance". Neste trabalho destacam-se as características épicas e romanescas de $O$ feliz independente, tendo como pano de fundo os debates poetológicos do século XVIII e as teses sobre os gêneros literários de Mikhail Bakhtin.
\end{abstract}

Palavras-chave: Teodoro de Almeida, Mikhail Bakhtin, poesia épica, romance

\begin{abstract}
This paper highlights the epic and novelistic characteristics of Teodoro de Almeida's hybrid narrative $O$ feliz independente (The Happy Independent, 1779) against the backdrop of eighteenth-century literary theory and Mikhail Bakhtin's theses on literary genres. For contemporaries, Almeida's work was an "epic poem in prose". Today we classify it as a "novel". Examining the meta-literary reflections of the author and the literary criticism that accompanied its publication, I demonstrate the volatile status of some paradigms of the epic genre, for example, the use of verse, of heroic deeds relating to a collectivity, and the conception of the hero. My analysis shows that late eighteenth century Portuguese epic poetry laid the groundwork for the historical novel of Romanticism through this process of renewal and transformation.
\end{abstract}

Keywords: Teodoro de Almeida, Mikhail Bakhtin, epic poetry, novel

No seu estudo Epos e Romance: Sobre a metodologia do estudo do romance (1941), Mikhail Bakhtin formula a tese notável de que, com o surgimento e desenvolvimento do romance, se reconhece uma luta histórica de gêneros literários, especialmente desde a segunda metade do século XVIII. Nas épocas em que o romance manteve a supremacia, quase todos os outros gêneros se tornaram mais ou menos "romanescos", porque o romance irradiava para os outros gêneros. O romance não se distingue apenas de outros gêneros literários, mas os parodia, integra, desloca e decompõe (Bakhtin, 1998, p. 399-400). Embora Bakhtin conheça muito bem os romances antigos e os analise repetidamente nos seus trabalhos, ele define o início do romance no Renascimento. Segundo o teórico russo, o romance é o gênero determinante no desenvolvimento histórico-literário da modernidade, pois reflete melhor do que todos os outros o desenvolvimento da modernidade. "[O] romance é o único gênero por se constituir, e ainda inacabado" (Bakhtin, 1998, p. 399). Em comparação com os outros "grandes gêneros", o

\footnotetext{
${ }^{1}$ Universidade de Salzburg, Salzburg, Austria; https://orcid.org/0000-0002-7449-3202 ;

markus.ebenhoch@sbg.ac.at
} 
romance é o único gênero que surgiu depois da invenção da escrita e dos livros impressos e que leva em conta o modo silencioso de recepção; além disso, não tem de aderir ao espartilho de um corpus restritivo. O romance distinguia-se de todos os outros gêneros por três particularidades fundamentais que estão ligadas organicamente entre si:

1. A "tridimensão estilística" (Bakhtin, 1998, p. 403), uma vez que a consciência plurilíngue manifesta-se no romance, e o multilinguismo torna-se um fator criativo. Isso mostrase em termos concretos, na medida em que o foco em uma única língua nacional chega ao fim e coexistem jargões, dialetos, bem como línguas de diferentes gêneros, discursos e épocas.

2. A "transformação radical das coordenadas temporais das representações literárias" (Bakhtin, 1998, p. 403), porque os determinantes do romance não são o passado nacional, mas a experiência, o conhecimento e a prática.

3. Assim, o romance situa-se na "área de contato máximo com o presente [...] no seu aspecto inacabado" (Bakhtin, 1998, p. 403), o seu material deriva principalmente da realidade contemporânea mais baixa ou encontra uma aproximação máxima através do riso ou da "familiarização" do material tradicional. O mundo é assim entendido como um fenômeno histórico e emergente (Bakhtin, 1998, p. 403-427).

Em contraste, a epopeia foi criada "há muito tempo" e é um "gênero já profundamente envelhecido" e "acabado" (Bakhtin, 1998, p. 397, 407). Em analogia à definição do romance, o teórico russo enumera três traços constitutivos para a epopeia:

1. "O passado nacional épico [...] serve como objeto da epopeia" (Bakhtin, 1998, p. 405), ou seja, as origens, os fastígios e os acontecimentos memoráveis da história nacional devem ser representados na epopeia. $\mathrm{O}$ autor e o leitor adotam uma atitude piedosa para com este passado sacrossanto e incontestável.

2. Enquanto o romance é baseado na experiência pessoal e imaginação, a "lenda nacional [...] atua como fonte da epopeia" (Bakhtin, 1998, p. 405). Quando se cantam canções heroicas em honra de figuras contemporâneas, estas vêm das classes sociais hierarquicamente mais elevadas e os padrões canonizantes, a "forma cronológica e axiológica do passado" (Bakhtin, 1998, p. 406), são transferidos para elas.

3. O mundo épico é separado do presente do autor e do ouvinte "por uma distância épica absoluta" (Bakhtin, 1998, p. 405). O mundo épico, que não é historicamente localizável, permanece num nível temporal e axiológico inatingível, é fechado e absoluto, imune a reinterpretações, reavaliações e intenções de continuação (Bakhtin, 1998, p. 405-411).

A tese bakhtiniana de que a luta histórica de gêneros literários termina na "romancização" dos outros gêneros, subsequentemente será discutida com base na narrativa híbrida em três volumes de $O$ feliz independente, de Teodoro de Almeida. Mas antes queria mencionar brevemente quem foi o autor deste texto literário, resumir o seu conteúdo e ilustrar alguns aspectos do debate poetológico setecentista sobre o poema épico. ${ }^{2}$

O padre oratoriano Teodoro de Almeida (1722-1804) foi professor de filosofia, fundador da Academia de Ciências de Lisboa e membro de várias instituições acadêmicas prestigiosas, como por exemplo The Royal Society em Londres. Almeida é considerado um dos mais importantes filósofos do Iluminismo católico em Portugal, mas, do ponto de vista atual, as suas obras completas parecem paradoxais, pois o Iluminismo é principalmente conotado com ceticismo em relação à religião, já que encontramos literatura edificante a par de tratados científicos. Por exemplo, nos dez tomos da Recreação filosófica (1751-1800), o seu opus magnum, Almeida dá um panorama sobre o status quo das ciências, um projeto similar à Encyclopadia Britannica e à Encylopédie de Diderot e D'Alembert. Viveu no final da época pombalina no exílio na França, onde escreveu a narração edificante $O$ feliz independente, que foi publicada pela primeira vez em 1779 e depois tornou-se um êxito editorial: cinco edições

\footnotetext{
2 Para desambiguação, estamos a usar o adjetivo "poetológico" quando falamos sobre a teoria dos gêneros literários e "poético", quando falamos das características atribuídas à poesia.
} 
em Portugal até 1861, a versão espanhola teve onze edições até 1884, as traduções para o francês e o alemão foram publicadas na década de 1820 (Azevedo, 1975; Borralho, 2001; Cidade, 1929, p. 104-115; Domingues, 1994; Govaski, 2019; Santos, 2002; Santos, 2007; Simões, 1987, p. 246-247).

A felicidade, um tema que estava em voga no século XVIII, aparece na primeira parte do título $O$ feliz independente do mundo e da fortuna. A segunda parte do título indica a intenção pedagógica do romance: Arte de viver contente em quaisquer trabalhos da vida. Por este motivo, e em concordância com a mensagem católica do texto, Almeida não situa a sua história num contexto pagão, mas seleciona um rei cristão como protagonista. Vladislau, uma figura histórica da monarquia polaca no início do século XIII, que abdicou do trono, dos privilégios reais e das riquezas para se converter em eremita. $\mathrm{O}$ texto descreve como o rei Vladislau, depois da sua conversão religiosa, tomou o nome Misseno e vive em solidão. Um dia, o conde da Morávia e a sua irmã Sofia, a mulher do antigo imperador de Constantinopla, encontram Misseno que, para eles, é a encarnação do homem feliz. O conde e Sofia, os dois à procura da felicidade, recebem o "remédio" contra as suas tristezas por parte de Misseno, por exemplo, numa conversa longa na qual também participa Ibraim, um erudito islâmico que ensina filosofia, matemática e ciências naturais aos filhos de Sofia. Mais tarde, Misseno torna-se mentor do conde de Morávia e acompanha-o na sua viagem à Terra Santa, onde o jovem cavalheiro quer participar na cruzada. Em profusos diálogos, o conde e Misseno, muitas vezes com outros interlocutores, falam sobre a legitimação e o exercício do poder, a tirania, o conceito da guerra justa, a procura da glória, a beleza feminina e os sentimentos humanos. As doutrinas de Misseno, que várias figuras secundárias recebem com agradecimento, não têm êxito no caso do conde. Arrastado pelas suas paixões e a melancolia, o conde acaba com a própria vida no final do enredo, e Misseno volta como eremita e conselheiro para a sua terra natal.

O discurso religioso está onipresente no Feliz independente. A intenção do autor foi conciliar o cristianismo com a filosofia do Iluminismo e por este motivo abordou a questão da felicidade, que estava na moda no discurso filosófico contemporâneo. A mensagem de Misseno, que na verdade é o alter ego do autor, pode-se resumir assim: os homens têm a capacidade de alcançar a felicidade caso orientem as suas vidas conforme a providência divina e atuem de modo racional e virtuoso. Isto quer dizer, domar as paixões que levam à ruína, e fazer boas obras no sentido da caridade cristã. Aos homens que procuram a felicidade, Deus ajuda-os com a sua palavra que se mostra na razão humana e na Bíblia.

O discurso religioso aparece ainda mais pronunciado e explícito nos paratextos antepostos à narração. Na invocação ao "Senhor", que só está incluída na editio princeps do ano 1799 , Almeida explica que o mundo e a vida humana constituem o âmbito de "aflições", "prantos" e "gemidos", no entanto, a graça divina muda o destino dos homens porque o "Deos Crucificado" ajuda e salva (Almeida, 1779, p. ii). Este conhecimento, resultado dos "estudos" do autor, resultou na sua obra espiritual Tezoiro de paciencia nas chagas de Jesus Cristo... (1768), mas Almeida reconhece que esta obra não teve o êxito esperado, motivo pelo qual "preparando o mesmo remedio de vossa [= Jesu Crucificado; ME] salutifera doutrina, de outro modo, o disfarcei com a apparencia do que todos geralmente gostão" (Almeida, 1779, p. v). No "Prólogo", menciona que a obra Les aventures de Télémaque (1699), de François Fénelon, foi uma fonte central de inspiração. Igual a Fénelon, Almeida segue o ditame da tradição horaciana delectare et prodesse, ou nas palavras do autor português, a mistura do "suave" com o "útil", dando "as máximas mais salutíferas para os costumes" "com a suavidade do néctar encantador da poesia", ou seja "disfarçando a austeridade das máximas evangélicas com a beleza e flores da razão e da poesia" (Almeida, 2002, p. 35). O principal motivo para escrever O feliz independente foi "o bem da humanidade", e Almeida começou a redação do manuscrito em "verso rimado", depois em "verso solto" e finalmente em prosa, pois precisava da liberdade linguística da forma amétrica para colocar os seus pensamentos no papel (Almeida, 2002, p. 
35). No "Prólogo" para $O$ feliz independente, além das considerações sobre a função e a forma do texto literário, Almeida inclui reflexões poetológicas sobre o protagonista, a constelação de personagens, a relação entre ficção e historicidade, assim como a construção do enredo narrativo. Com respeito a isso, o padre oratoriano declara que procurou um "herói verdadeiro na história", que fosse um modelo de virtude e uma "pintura da felicidade", porque os homens animam-se a fazer o que já foi praticado, desde que os efeitos sejam agradáveis, e acrescenta:

[A]ssentei que o [= o herói; ME] devia buscar entre os príncipes cristãos, para que ninguém pudesse suspeitar que eu fazia nascer a felicidade das máximas independentes da religião romana, que é a única em que podemos ser felizes na vida e esperar a completa felicidade depois da morte. Este ponto era essencialíssimo para que não confundisse ninguém a minha filosofia com a filosofia pagã; e as máximas tiradas do Evangelho com os conselhos de Platão ou de Séneca ou daqueles falsos filósofos que, nos nossos tempos, vendem com o especioso título do Bem da Sociedade, os proscritos e já desprezados erros dos antigos sofistas. (Almeida, 2002, p. 36-37).

A última parte da citação é muito provavelmente uma alusão aos philosophes franceses ou aos empiristas ingleses. Como mencionado, Almeida teve êxito na sua procura de um herói verdadeiro na história, e põe ao lado do rei Vladislau, aliás Misseno, o conde de Morávia que atua não só como discípulo do protagonista, mas também como antagonista. No papel de antagonista ilustra os efeitos desastrosos dos vícios que acabam na catástrofe final. Curiosamente Almeida justifica a sua decisão para esta constelação de personagens com um argumento poetológico que atinge o sistema de gêneros literários:

[E]ra-me necessário outro personagem contemporâneo, para que não dissesse alguém que degenerava em novela, o que era poema (ainda que pudesse tomar a licença que tomaram Virgílio, Tasso e outros, valendo-se de personagens que não coexistiram). (Almeida, 2002, p. 37).

Obviamente o status quo do gênero literário "novela", ou seja, o romance, era muito inferior ao do poema épico e para isso a ruptura com o critério da verosimilhança era um fator importante no raciocínio do padre oratoriano. Almeida sublinha que a cronologia e a riqueza dos acontecimentos históricos no início do século XIII eram favoráveis à estruturação do enredo narrativo e ao seu efeito nos leitores. Nas palavras do autor:

Tudo isto fornecia à ficção poética mil episódios que podiam ser úteis à intriga; a qual serve não só para fazer ver as paixões, em toda a sua força, mas para trazer a alma do leitor em contínuo, mas diferente e agradável movimento. (Almeida, 2002, p. 37-38).

A terminologia e os conceitos que Almeida utiliza nos seus dois paratextos correspondem em grande medida ao discurso poetológico setecentista. Detemo-nos nas explicações sobre o poema épico na Arte poética que Francisco José Freire publicou em 1748, talvez tendo como base os tratados Della perfetta poesia italiana (1706), de Ludovico Antonio Muratori, e Poética (1737), de Ignacio de Luzán. Nos primeiros doze capítulos do livro III, o "Cândido Lusitano" da Arcádia Lusitana trata da natureza da epopeia, das propriedades da ação heroica, do herói, das intervenções divinas no enredo, das partes necessárias da epopeia (ou seja, do título, da proposição, da invocação e da narração), assim como do uso da alegoria e da paródia no poema épico. Termina a sua exposição sobre a epopeia com alguns comentários sobre os antigos poetas épicos gregos e latinos e com o seu juízo sobre os Lusíadas. Freire define a epopeia da maneira seguinte: 
Dizemos pois, que a Epopeia he a imitaçã̃ de huma acçaõ heroica, perfeita, e de justa grandeza, feita em verso heroico por modo mixto, de maneira, que cause huma singular admiraçaõ, e prazer, e ao mesmo tempo excite os animos a amar as virtudes, e as grandes emprezas (Freire, 1748, p. 300; destaque no original).

Referindo-se à função literária, Freire explica que a tragédia causa terror e compaixão, a comédia esperança e gosto, enquanto que a epopeia causa admiração e prazer, e desenvolve as virtudes nos destinatários. Com respeito à forma literária, acha que o verso heroico, que nas "línguas vulgares" corresponde ao "hendecasyllabo, e mais propriamente as outavas", pela sua harmonia e gravidade, seja o mais adequado ao poema épico (Freire, 1748, p. 299-301). "Modo mixto" significa que a fala do poeta mesmo mistura-se com a fala dos personagens literários, criando um efeito dramático. Segundo Cândido Lusitano, a ação heroica possui sete propriedades: "deve ser grande, unica, de duraçaõ determinada, de exito feliz, fundada na

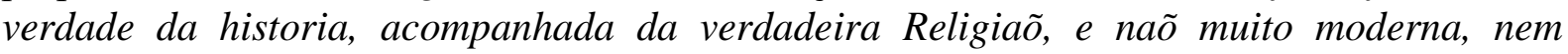
demasiadamente antiga" (Freire, 1748, p. 303; destaque no original) e especifica a "verdadeira Religiaõ":

A sexta propriedade he, que a acçaõ seja acompamhada com a verdadeira religiaõ; porque, como o Heroe necessita de huma particular ajuda de Deos, para conseguir o fim da sua grande acçaõ, deve perfeitamente observar a piedade, religiaõ, justiça, e todas as demais virtudes. (Freire, 1748, p. 308; destaque no original).

Apesar de que o herói épico precise da ajuda divina para a suas proezas, porque afinal também o herói é um homem imperfeito, a introdução de forças sobrenaturais nunca o deve deslustrar. Não só ele, mas também a "admirabilidade" e o "maravilhoso" épico relacionam-se com entidades religiosas, concretamente com as "falsas divindades" no caso dos "Poetas gentios" e com Deus, os anjos, os santos, as virtudes sobrenaturais e os demônios no caso dos poetas católicos, embora Freire aceite a possibilidade de que numa epopeia de pena católica apareçam expressões pagãs, por exemplo, para substituir os dotes da natureza por divindades, como a formosura por Vênus, o valor por Marte, etc. (Freire, 1748, p. 302-316).

O segundo tratado poetológico que queremos apresentar é o "Discurso preliminar" do professor de retórica e poética António das Neves Pereira, que precede $O$ feliz independente desde a segunda edição, do ano 1786. Na primeira parte expõe as regras gerais do poema épico e distingue entre a "crítica vulgar" e a "crítica judiciosa" da poesia épica; na segunda parte, dedica-se particularmente ao texto de Almeida e analisa o gênero literário, a matéria, o "maravilhoso" ou "admirável" da ação épica, a composição textual, as comparações e o estilo poético. Neves Pereira repetidamente toma posição contra a imitação servil dos modelos antigos e explica que a versificação não é decisiva para a poesia épica. Pelo contrário, "uma maior plenitude de ideias e de sentimentos que fornece a imaginação, junto a um certo colorido e harmonia" (Pereira, 2002, p. 58-59) contribuem para o estilo poético que se realiza também em forma de prosa. Neves Pereira categoriza $O$ feliz independente como "poema épico em prosa", que, igualmente à epopeia versificada tradicional, sabe deleitar e instruir (Pereira, 2002, p. 47, 50). Em contraste com as epopeias antigas, que se concentravam nas ações bélicas do herói, "não consente a pureza e santidade de nossa religião fixar a ideia do heroísmo como os cegos

\footnotetext{
${ }^{3}$ Depois da "Reforma de Castilho", que se baseia no Tratado de versificação portuguesa para em pouco tempo e até sem mestre se aprender a fazer versos de todas as medidas e composições (1851), de António Feliciano de Castilho, só se conta as sílabas de cada verso até à última sílaba acentuada, ao passo que antes disso dominava o método de contagem de sílabas espanhol ou italiano. Portanto, o verso heroico determinado por Freire como hendecassílabo corresponde ao decassílabo na terminologia atualmente utilizada.
} 
gentios, em derramar muito sangue humano" (Pereira, 2002, p. 53). Segundo Neves Pereira, a grandeza e a glória do herói encontram-se na sua alma, núcleo para constituir um poema épico cristão. Igual a Freire, Neves Pereira reconhece que o essencial do poema épico consiste na narração que deve ter um corpo bem formado, uma boa disposição e uma ação única, interessante e completa. No seu "Discurso preliminar", nota-se também uma atitude negativa para com o "romance ou novela", porque este gênero literário "excede os limites da verosimilhança e do moralmente possível", embora aceite o maravilhoso como ornato ou decoração do assunto poético (Pereira, 2002, p. 50, 54).

De seguida tentamos responder à pergunta inicial que deduzimos do ensaio bakhtiniano Epos e romance e que dá o título a este trabalho: a epopeia e o romance estão em conflito na narrativa $O$ feliz independente? Num primeiro momento, queremos ressaltar seis técnicas e conceitos presentes no texto de Almeida que normalmente se relacionam com a epopeia, tendo em conta os debates poetológicos do século XVIII antes resumidos:

1. Compêndio do conhecimento contemporâneo. Almeida não se limita à lenda nacional como fonte da epopeia, nem sequer menciona Portugal no seu texto, mas, baseando-se nos seus estudos sobre a época medieval, deixa o enredo seguir o seu curso na Europa do Este, na Europa do Sudeste e na Ásia Menor. Nos discursos dos personagens e também nas notas de rodapé estão expostos muitos dados históricos, por exemplo, genealogias reais da Polônia ou de Constantinopla, o que se encaixa na poética da epopeia, funcionando tradicionalmente como um meio de armazenamento do conhecimento contemporâneo (Auerochs, 2002, 200; Friedlein, 2014).

2. Destinatários. A narrativa sobre feitos heroico-históricos relevantes para uma coletividade, aqui a cristandade do Iluminismo, situa-se no tempo das cruzadas no início do século XIII. Conforme às exigências poetológicas, O feliz independente quer deleitar e instruir os seus leitores. Os destinatários deste texto edificante são em primeiro lugar os leitores cristãos, no entanto, pela estruturação dialógico-argumentativa da obra que tenta criar e fomentar um efeito persuasivo mostrando um caminho cristão para a felicidade, proponho a tese de que os deístas e ateus iluminados também devem ser considerados como destinatários do texto.

3. Composição da obra e estrutura da narração. Como "poema épico em prosa", O feliz independente observa a composição tripartida da epopeia (Auerochs, 2002, p. 200-202; Reis; Lopes, 2002, p. 130-131). O paratexto "Senhor" inclui uma invocação, o paratexto "Prólogo" tem as características centrais de uma proposição e nos extensos três tomos realiza-se a parte central da epopeia, a narração. Na estrutura narrativa, as analepses, que frequentemente se encontram nas epopeias desde a Odisseia de Homero, estão integradas em cenários de diálogo, de acordo com o antigo pretexto. $\mathrm{O}$ enredo inaugura in medias res e, de fato, o primeiro tomo constitui um prolongado flashback, no qual o protagonista maduro Misseno explica aos seus ouvintes, o conde de Morávia, Sofia e Ibraim, a sua vida cheia de acontecimentos fatais. As ações do segundo tomo têm lugar à beira do rio Dniestre, onde aconteceu o encontro inicial destes personagens. Só para o final do segundo tomo começa a viagem de Misseno com o conde de Morávia em direção à Terra Santa, que acaba com o suicídio do conde e o regresso de Misseno à sua terra natal, a Polônia.

4. Estilo. Todo o enredo da narração é apresentado no "modo mixto", ou seja, na fala do narrador e dos personagens, que não se distinguem estilisticamente. No que diz respeito à elaboração linguística, Almeida dá importância a um estilo poético e ao mesmo tempo claro, para fortalecer sua intenção moralizadora. Apesar de renunciar à versificação, o padre oratoriano valoriza o ritmo, a seleção vocabular e a metáfora para escrever "na liberdade da prosa", mas conservando "as leis da poesia" (Almeida, 2002, p. 36). Segundo Zulmira Santos, a sua elaboração linguística ajusta-se ao estilo solene típico da epopeia (Santos, 2002, p. 1821). 
5. Concepção do herói e escolha de personagens. Os protagonistas e também uma grande parte dos personagens secundários são todos personalidades de alto nível, como reis, príncipes, cavalheiros, comandantes, bispos, embaixadores, etc. Nas suas conversas concentram-se principalmente em questões de legitimação do poder e do seu exercício, assim como no domínio das paixões - neste ponto, Almeida segue as pautas de Les aventures de Télémaque, de François Fénelon, que fica na linha da tradição dos espelhos de príncipes. Ao contrário de Fénelon, o autor português dá importância ao fato de que seu herói era cristão e encontra-se historicamente atestado porque, segundo ele, os modelos históricos convidam mais à imitação. Curiosamente os destinatários diegéticos, isto quer dizer os destinatários dentro do mesmo enredo, que cumprem os conselhos de Misseno, são principalmente mulheres: Sofia, Hermila, a filha do governador da fortaleza onde Misseno está preso, Ifigênia, a escrava do sultão de Icónio que recebe apoio espiritual do protagonista, etc. Entre os homens que ouvem as "doutrinas salutíferas" de Misseno há vários que não as obedecem e não praticam comportamentos exemplares, como o conde de Morávia, Ibraim ou Neucasis, o capitão de um navio veneziano. O fim trágico do conde de Morávia também trouxe crítica dos contemporâneos. Andrés Merino, autor do romance espanhol La muger feliz, dependiente del mundo y de la fortuna (1786), obviamente inspirado pela obra literária do oratoriano, declarou que o suicídio do conde ia "contra las reglas de la epopeya, cuyo fin debe ser feliz, no trágico" (Merino, 1789, IX).

6. Admirabilidade e maravilhoso. Mesmo no período neoclássico, no "século da razão", elementos fantásticos eram tolerados, desde que servissem como instrução moral. Conforme às regras poetológicas da epopeia que aceitam e até exigem "deidades" e "maquinas" que intervêm na ação e apoiam o herói, Almeida introduz anjos, santos, ninfas celestes, espíritos malignos e fúrias infernais no enredo do Feliz independente. Aqui o maravilhoso está baseado em conceitos religiosos cristãos: todos os milagres, as viagens para o templo das paixões, para o país da razão ou para a corte celestial, as ajudas divinas e intervenções infernais ajustam-se a uma visão abrangente da realidade que também leva em conta a transcendência. Desta maneira, podemos situar a obra de Almeida no gênero literário do poema épico cristão. Um estudo comparativo com algumas obras emblemáticas deste gênero, por exemplo, as epopeias bíblicas Paradise lost (1667), de John Milton, e Messias (1773), de Friedrich Gottlieb Klopstock, seria interessante.

Como segundo passo, queremos ressaltar cinco técnicas e conceitos presentes no texto de Almeida que o tornam "romanesco":

1. Historicidade. Segundo Bakhtin, o mundo narrado do romance pode-se situar historicamente e não escapa às origens míticas das culturas nacionais, por conseguinte, o mundo e os seus valores são emergentes e estão num processo de transformação contínuo. Como já foi mencionado, o mundo narrado do Feliz independente, em grande parte, é localizável historicamente no início do século XIII e geograficamente na Europa do Este, na Europa do Sudeste e na Ásia Menor. A fim de reafirmar a verdade histórica, científica e religiosa ( $o$ verdadeiro) e a sua probabilidade (o verosímil), Almeida introduz notas de rodapé a partir da segunda edição em diante, nas quais se refere a textos historiográficos, científicos e bíblicos. Isto também se deve à crítica contemporânea aos elementos fantásticos e à censura, que criticava o estoicismo latente da obra. Apesar da sua acentuada historicidade, o texto de Almeida não deve ser classificado como romance histórico, pois as passagens alegóricas e a intenção marcadamente edificante obstruem tal categorização. Na sua análise das referências contemporâneas e dos elementos autobiográficos, Santos conclui que a história de um rei polaco temente a Deus e virtuoso que abdica pacificamente do trono foi muito provavelmente compreendida pelos leitores contemporâneos como uma alusão ao rei polaco Estanislau Leszczyński (1677-1766), que encontrou um destino semelhante. Além disso, Santos lê as passagens críticas sobre os maus conselheiros reais e os tiranos como uma crítica implícita ao mau vassalo Pombal ou ao seu governo arbitrário, e vê paralelos entre a experiência do exílio de Almeida e a do seu alter ego literário (Santos, 2004; Santos, 2007, p. 349-350, 366). 
2. Prosa. Os paradigmas neoclássicos o verdadeiro e o verosímil não só determinam o enredo historicamente fundamentado, o inventário adequado dos personagens e a filosofia propagada, mas também podem ser aplicados à forma linguística, pois, ao optar por um texto em prosa, Almeida aproxima sua linguagem literária da linguagem quotidiana que, segundo Bakhtin, é a forma linguística que caracteriza o romance.

3. Gêneros incorporados. Com exceção de nove textos em verso, quase a totalidade do Feliz independente está escrita em prosa. No caso dos textos em verso, trata-se de árias, canções, cantigas, coplas e uma carta que principalmente são cantadas ou recitadas por Misseno e Sofia para o prazer do público ouvinte e para o instruir (Almeida, 2002, p. 65, 67, 74, 89, 141, 165, 198-200, 219-224, 256-257). Com este procedimento, Almeida retoma uma técnica do romance pastoril que ainda no século XVIII estava na moda. Em muitos casos estas passagens sintetizam a filosofia de Misseno e reafirmam a mensagem moral da obra; no entanto, dividem a unidade linguística do texto e assim contribuem para a sua tridimensão estilística.

4. Estrutura dialógica. A polifonia no romance mostra-se principalmente na diferenciação ideológica e não na diferenciação fraseológica - esta última leva à heteroglossia, segundo Bakhtin. No romance polifônico coexiste uma pluralidade de opiniões conflituosas e os personagens são seres autônomos com visões da realidade divergentes (Bauer, 2005, 124-129). O diálogo é o lugar preferencial para o encontro e confronto das opiniões conflituosas, o que está onipresente na obra de Almeida. Aqui, em extensos diálogos, personagens de culturas diferentes (o rei polaco, o conde de Morávia, o capitão do navio veneziano, turcos islâmicos, etc.) articulam suas visões do mundo e fornecem perspectivas para as suas vidas interiores e conflitos mentais. Apesar da estrutura dialógica que impregna toda a obra de Almeida, é preciso notar que $O$ feliz independente não corresponde à conceção bakhtiniana de um romance polifônico, já que, em última instância, o católico por excelência Misseno triunfa sobre as outras vozes textuais.

5. Revalorização do indivíduo. Em contraste com os heróis das epopeias, os protagonistas dos romances não são estáticos, mas evoluem em conformidade com as experiências que vão fazendo, os golpes do destino e novos desafios. Isto leva, segundo Bakhtin, a uma revalorização do indivíduo, da subjetividade e da iniciativa pessoal no romance. Pelo menos para o conde de Morávia e para Misseno esta tese é válida para a maior parte do texto.

Resumindo, $O$ feliz independente apresenta muitos traços que podem ser atribuídos à poesia épica, sobretudo a composição da obra, a estrutura da narração e a escolha de personagens de alto nível social. Embora faltem certas características centrais na conceção bakhtiniana do romance (contato máximo com o presente, familiarização, metaficção, paródia, polifonia), encontramos alguns elementos "romanescos" no texto. Possivelmente a localização histórica, a estrutura dialógica, o enfoque nas vidas interiores dos protagonistas e alguns conselhos espirituais tenham contribuído para o êxito editorial internacional desta obra nas décadas seguintes à primeira edição de 1779. Será o texto de Almeida um missing link entre as epopeias do início da Idade Moderna e os romances históricos e sentimentais do século XIX em Portugal? Pelo menos a boa recepção por parte dos leitores do século XIX parece sugerir isso, o que causou certa irritação na crítica literária posterior. Nas palavras pontiagudas de João Gaspar Simões:

Surpreende-nos hoje como foi possível o êxito extraordinário desta obra, mortalmente tedioso. Por pouco que disputava a palma aos leitores de Eça de Queirós. Venerada, especialmente, por um público recrutado entre a burguesia beata, mais apta para adquirir a obra do que a lê-la, para conservar ao lado do breviário, como uma espécie de credencial ortodoxa [...]. (Simões 1987, 249). 


\section{REFERÊNCIAS}

ALMEIDA, Teodoro de. O feliz independente. Ed. Zulmira C. Santos. Porto: Campo das Letras, 2002.

ALMEIDA, Theodoro de. O feliz independente do mundo e da fortuna, ou Arte de viver contente em quaisquer trabalhos da vida. Lisboa: Na Regia Officina Typografica, 1779.

AZEVEDO, Fernando. A Piety of the Enlightenment: The Spirituality of Truth of Teodoro de Almeida. Didaskalia, no. V, 1975, p. 105-131.

AUEROCHS, Bernd. Epos. Burdorf, Dieter; Fasbender, Christoph and Moennighoff, Burkhard, eds. Metzler Lexikon Literatur. 3. ed. Stuttgart; Weimar: Metzler, 2007, p. 200-202.

BAKHTIN, Mikhail. Questões de literatura e de estética: a teoria do romance. Trad. Aurora F. Bernadini et al. 4. ed. São Paulo: Editora UNESP, 1998.

BAUER, Matthias. Romantheorie und Erzählforschung: Eine Einführung. 2. ed. Stuttgart; Weimar: Metzler, 2005.

BORRALHO, Maria Luísa Malato. Teodoro de Almeida: entre as histórias da História e da Literatura. In: POLÔNIA, Amélia et al., eds. Estudos em homenagem a João Francisco Marques. v. 1. Porto: Faculdade de Letras da Universidade do Porto, 2001, p. 213-227.

CIDADE, Hernâni. Ensaio sobre a crise mental do século XVIII. Coimbra: Imprensa da Universidade 1929.

DOMINGUES, Francisco Contente. Ilustração e catolicismo: Teodoro de Almeida. Lisboa: Colibri, 1994.

FREIRE, Francisco Joseph. Arte poética, ou Regras da verdadeira poesia em geral, e de todas as suas espécies principaes, tratadas com juizo critico. Lisboa: Na Officina de Francisco Luiz Ameno, 1748.

FRIEDLEIN, Roger. Kosmovisionen: Inszenierungen von Wissen und Dichtung im Epos der Renaissance in Frankreich, Portugal und Spanien. Stuttgart: Steiner, 2014.

GOVASKI, Patrícia. Educação e filosofia moral na obra do Padre Teodoro de Almeida (17221804). Revista de História e Historiografia da Educação, Curitiba, v. 3, no. 7, 2019, p. 161181, http://dx.doi.org/10.5380/rhhe.v3i7.66159

MERINO, Andrés [= El Filósofo Incognito]. La muger feliz, dependiente del mundo y de la fortuna. 3. ed. Madrid: Imprenta Real, 1789.

PEREIRA, Antônio das Neves. Discurso Preliminar Sobre o Poema do Feliz independente. In: ALMEIDA, Teodoro de. O feliz independente. Ed. Zulmira C. Santos. Porto: Campo das Letras, 2002, p. 39-60.

REIS, Carlos; LOPES, Ana Cristiana M. Dicionário de narratologia. 7. ed. Coimbra: Almedina, 2002. 
SANTOS, Zulmira C. Discurso do passado, discursos do presente: os cruzamentos da 'história' em $O$ feliz independente (1779), de Teodoro de Almeida. In: MARINHO, Maria de Fátima, ed. Literatura e História - Atas do Colóquio Internacional. v. II. Porto: Faculdade de Letras do Porto, 2004, p. 217-224.

SANTOS, Zulmira C. Introdução. In: ALMEIDA, Teodoro de. O feliz independente. Ed. Zulmira C. Santos. Porto: Campo das Letras, 2002, p. 7-23.

SANTOS, Zulmira C. Literatura e espiritualidade na obra de Teodoro de Almeida (1722-1804). Lisboa: Fundação Calouste Gulbenkian, 2007.

SIMÕES, João Gaspar. Perspectiva histórica da ficção portuguesa (das origens ao Século XX). 2. ed. Lisboa: Dom Quixote, 1987.

Markus Ebenhoch - Doutor em Letras e professor pela Universidade de Salzburg (Áustria), foi professor convidado da Universidade de Lisboa entre 2016 e 2017. É autor de "Antônio José da Silva, as Obras do diabinho da mão furada e a Inquisição Portuguesa" (2017). https://orcid.org/0000-0002-7449-3202.

Submetido em 11/01/2020

Aceito em 22/03/2020 